\title{
The Growth Factor and Amino Acid Requirements of Species of the Genus Leuconostoc, including Leuconostoc paramesenteroides (sp.nov.) and Leuconostoc oenos
}

\author{
By ELLEN I. GAR VIE \\ National Institute for Research in Dairying, Shinfield, Reading \\ (Accepted for publication 24 March 1967)
}

SUMMAR Y

The vitamin requirements of 63 strains and the amino acid requirements of 40 strains belonging to the genus Leuconostoc have been determined. The amino acid requirements separate the genus into dextran and non-dextran formers and in particular indicated that non-dextran formers should be excluded from Leuconostoc mesenteroides. The growth factor requirements support the division of the leuconostocs by other methods into six species: Leuconostoc mesenteroides, L. dextranicum, L. paramesenteroides, L. lactis, L. cremoris and L. oenos.

\section{INTRODUCTION}

No previous studies of the vitamin and amino acid requirements of leuconostoc strains has included representatives from all the species of the genus, but reports have been confined to strains selected either by habitat or species. Dunn, Shankman, Camien \& Block (1947) and Shankman et al. (1947) examined a variety of lactic acid bacteria which included eight leuconostocs, all dextran formers (although some were designated Leuconostoc citrovorum), and Whiteside-Carlson \& Carlson (1949) and Whiteside-Carlson \& Rosano (I95I) worked only with strains which made dextran. In the dairy field, Prouty (I96I) examined cultures of L. dextranicum and L. citrovorum isolated from starters. Radler (I958) studied three strains isolated from wine and Peynaud, Lafon-Lafourcade \& Domercq (1965) included 37 heterofermentative cocci in their study of the nutrition of lactic acid bacteria from wine. The media and methods used in all these experiments differed considerably and it is not easy therefore to compare the requirements of the different species.

In the present work strains of all the known species of leuconostoc have been used, i.e. representatives from the six groups reported by Garvie (1960) and also from the acidophilic strains found in wine (Garvie, 1967).

\section{METHODS}

Strains. The strains were all from the National Collection of Dairy Organisms (NCDO), Shinfield, and the NCDO accession numbers of those used are given in Table I. Many of the strains were included in earlier work (Garvie, 1960) but others have been deposited in the NCDO since the completion of that work, namely strains NCDO I 583-I 598 by the National Collection of Industrial Bacteria (NCIB; Torry 
Research Station, Aberdeen); NCDO I563, I568 and I659 by Dr R. Whittenbury (East of Scotland Agricultural College, Edinburgh); NCDO I 656 by Dr C. J. A. van den Hamer (Utrecht, Holland); NCDO I668-1675 by Dr E. Peynaud (Station Agronomique et Oenologique de Bordeaux); NCDO I694-I696 by Dr F. Radler (Merbein, Victoria, Australia); and NCDO I389 by Dr P. R. Elliker (Oregon, U.S.A.).

Table I. Leuconostoc strains examined for growth factor and amino acid requirement

\begin{tabular}{|c|c|c|c|c|}
\hline \multirow[b]{2}{*}{ Group } & \multicolumn{4}{|c|}{$\begin{array}{l}\text { NCDO numbers of the strains } \\
\text { examined for }\end{array}$} \\
\hline & Species & $\begin{array}{l}\text { Growth factor and } \\
\text { amino acid requirement }\end{array}$ & $\begin{array}{l}\text { Growth factor re- } \\
\text { quirement only }\end{array}$ & $\begin{array}{c}\text { Strains examined by } \\
\text { other workers }\end{array}$ \\
\hline I & L. cremoris & $\begin{array}{l}543,705,1033 \\
1071,1389\end{array}$ & 828 & . \\
\hline II & L. lactis & $532,533,546$ & $549,956,959$ & . \\
\hline III & L. paramesenteroides & $\begin{array}{l}803,871,1563 \\
1568,1569,1590\end{array}$ & $\begin{array}{c}870,883,955,957 \\
958,1589,1656\end{array}$ & . \\
\hline IV & L. dextranicum & $517,824,1591$ & $529,531,862$ & 824 \\
\hline V & L. dextranicum & $\begin{array}{l}183,516,550 \\
1582\end{array}$ & $\begin{array}{l}537,812,861 \\
880,1592,1598\end{array}$ & 516 \\
\hline VI & L. mesenteroides & $\begin{array}{l}518,519,522,523, \\
551,768,1583, \\
1584,1585,1587\end{array}$ & $\begin{array}{l}527,538,54 \mathrm{I} \\
797,807,876 \\
1588, \text { I } 593, \text { I } 594\end{array}$ & $\begin{array}{l}518,519,522 \\
551,523\end{array}$ \\
\hline VII & L. oenos & $\begin{array}{l}1668,1669,1671, \\
1672,1673,1674, \\
1675,1694,1695\end{array}$ & I696 & I694, I695, I696 \\
\hline
\end{tabular}

Media for maintaining cultures. The cultures were grown in the media used by Garvie (1967), yeast glucose citrate broth (YGCB) for groups I-VI and acidic tomato broth (ATB) for group VII. A I \% (w/v) solution of cysteine hydrochloride was sterilized by Seitz filtration and $0.5 \mathrm{ml}$. added/Io ml. media for strains of group I (Leuconostoc cremoris; Betacoccus cremoris Knudsen \& Sørensen (1929)) and group VII (L.oenos). These species were incubated at $22^{\circ}$, most strains of other species were incubated at $30^{\circ}$, but a few strains of groups III and IV grew better at $22^{\circ}$ and the growth of these was helped by the addition of cysteine hydrochloride. Incubation was generally for $24 \mathrm{hr}$ but some cultures, particularly those at $22^{\circ}$, required $48 \mathrm{hr}$ or longer.

Media for determining requirement for amino acids and vitamins. The amino acid requirements were estimated in medium $\mathrm{A}$ (Table 2) from which each amino acid was omitted in turn. This medium was similar to that used by Reiter \& Oram (1962) and is based on the amino acid analysis of milk. It was used, because before devising YGCB it had been observed that some strains of Leuconostoc cremoris grew more readily in milk supplemented with Yeastrel and glucose than in the broth medium used at that time.

The vitamin requirements were assessed in medium B (Table 2) from which each growth factor was omitted in turn and in which vitamin-free acid-hydrolysed casein and vitamin-free enzymic digest of casein were substituted for the amino acid mix of 
medium A. The acid-hydrolysed casein was prepared by the method of Ford, Perry \& Briggs (1958) but with an additional $200 \mathrm{mg}$. cystine added to the filtrate from $50 \mathrm{~g}$. casein. The enzymic digest of casein was prepared according to Roberts \& Snell (1946). Media A and B were dispensed in $5 \mathrm{ml}$. quantities in 6 in. $\times \frac{5}{8}$ in. test tubes, closed with metal caps and sterilized by autoclaving at $115^{\circ}$ for $10 \mathrm{~min}$. and cooled immediately in cold water.

\section{Table 2. Composition of media for examining amino acid and growth factor requirements of strains of leuconostocs}

All media were prepared at $\mathrm{pH} 5.0$ for Leuconostoc oenos and $\mathrm{pH} 6.7$ for other species.

\begin{tabular}{|c|c|}
\hline Glucose & $10 \mathrm{~g}$. \\
\hline Sodium acetate $\left(3 \mathrm{H}_{2} \mathrm{O}\right)$ & $2 \mathrm{~g}$. \\
\hline Triammonium citrate & $2 \mathrm{~g}$. \\
\hline $\mathrm{K}_{2} \mathrm{HPO}_{4}$ & $2 \mathrm{~g}$. \\
\hline $\mathrm{KH}_{2} \mathrm{PO}_{4}$ & $2 \mathrm{~g}$ \\
\hline $\mathrm{MgSO}_{4} \cdot 7 \mathrm{H}_{2} \mathrm{O}$ & $0.2 \mathrm{~g}$. \\
\hline $\mathrm{MnSO}_{4} \cdot 4 \mathrm{H}_{2} \mathrm{O}$ & $0.05 \mathrm{~g}$. \\
\hline $\mathrm{FeSO}_{4} \cdot 7 \mathrm{H}_{2} \mathrm{O}$ & $0.05 \mathrm{~g}$. \\
\hline Tween 80 & I $\mathrm{ml}$. \\
\hline Guanine & $5 \mathrm{mg}$. \\
\hline Adenine & $5 \mathrm{mg}$. \\
\hline Uracil & $5 \mathrm{mg}$. \\
\hline Xanthine & $5 \mathrm{mg}$. \\
\hline Pyridoxal & $2 \mathrm{mg}$. \\
\hline Nicotinic acid & I $\mathrm{mg}$. \\
\hline Calcium-D-pantothenate & I mg. \\
\hline Riboflavin & I $\mathrm{mg}$. \\
\hline Thiamine & I mg. \\
\hline Vitamin $\mathbf{B}_{12}$ (cobalamin) & I $\mu \mathrm{g}$. \\
\hline Biotin & Iо $\mu \mathrm{g}$. \\
\hline p-Amino benzoic acid & $5 \mu$ \\
\hline Folic acid & IO $\mu$ \\
\hline Total volume & $1000 \mathrm{ml}$. \\
\hline
\end{tabular}

Determination of amino acid requirements. Cultures were transferred from YGCB or ATB to a tryptone broth (medium C, Table 2), of the appropriate initial $\mathrm{pH}$ value and with the addition of cysteine hydrochloride for strains of groups I and VII. Cultures of strains from groups I and VII required several transfers through medium $\mathrm{C}$ before rapid growth was obtained. Strains of other groups were transferred twice. One drop of a culture in medium $\mathrm{C}$ was inoculated into each of the amino acid test media (media $\mathrm{A}$ ) and the tubes incubated at the appropriate temperature. It was necessary to add cysteine to medium $\mathrm{A}$ when testing groups I and VII strains but not for strains of other groups. Cysteine was omitted when a requirement for cystine was being examined.

The time of incubation could not be standardized because the differences in growth rate between the cultures was even greater than in the general media. Incubation was continued until the complete medium showed good growth. With many strains $24 \mathrm{hr}$ was adequate, but with others incubation was prolonged to 7-10 days. Growth was 
estimated photometrically as the extinction at $580 \mathrm{~m} \mu$ with a Hilger Biochem absorptiometer.

Determination of growth factor requirements. One drop of a culture in YGCB or ATB was inoculated into a series of tubes of medium B, each deficient in one growth factor and into the complete medium. The inoculated tubes were incubated at the appropriate temperature until good growth in the complete medium was observed. The cultures were transferred twice more through medium B of the same composition and the requirement for a particular growth factor assessed by the presence or absence of growth in the third subculture. As before, cysteine was added to cultures of groups I and VII.

Determination of a biotin requirement. A requirement for biotin was estimated in the same way as for the other vitamins but using medium to which $0.002 \mathrm{ml}$. egg white $/ \mathrm{ml}$. had been added to bind any traces of biotin in the medium (Broquist \& Snell, I948). Broquist \& Snell (I95I) reported a relationship between a requirement for oleate and biotin in some lactic acid bacteria. In the present experiments a requirement for one of these substances was determined in the presence of the other.

\section{RESULTS}

Patterns of vitamin requirements of species have proved useful in supporting the classification of the lactobacilli by other criteria (Rogosa \& Sharpe, I959), and this study of the vitamin and amino acid requirements of the leuconostocs was made to see whether in this genus also the results would assist in the definition of species.

\section{Amino acid requirements}

The amino acid requirements observed are summarized in Table 3. As with many other properties of the leuconostocs the amino acid requirements were found to be variable between different strains of any species. Only valine and glutamic acid were required by all strains, and methionine was markedly stimulatory for most. No requirement for alanine was observed for any strain. Each of the other 14 amino acids were individually required by, or stimulatory to, some strains.

Table 4 gives the numbers of amino acids required by strains. It shows that the genus can be divided into two groups: (I) the dextran-forming strains of groups IV, $\mathrm{V}$ and VI, where each strain requires a few (up to 8) amino acids; (2) strains not forming dextran where each strain requires a larger number $(>8)$ of amino acids. On the basis of the numbers of amino acids needed by each strain, groups VI and III are different. Previously they have been put together in one species but they can be separated on the basis of their amino acid requirements.

Cultures of groups I and VII were slow to grow in the medium used and the final turbidity was low in some instances, even after prolonged incubation (7-10 days).

\section{Growth factor requirements}

The growth factor requirements are shown in Table 5. Only five group VII strains are included because the other I I strains examined did not grow. The group VII strains for which results are given were slow to grow in the medium $\mathrm{B}$; why more strains grew in medium $A$ than in medium $B$ is not clear, since medium $A$ contained amino acids whereas medium $B$ contained enzymic digest and acid-hydrolysed casein 
as nitrogen source and cultures would be expected to grow better in the latter medium. Media A and B were not satisfactory for this group of leuconostocs; further work on the nutrition of species is reported elsewhere (Garvie \& Mabbitt, 1967).

Table 3. Amino acid requirements of strains of Leuconostocs. Medium $A$ was used and amino acids omitted singly.

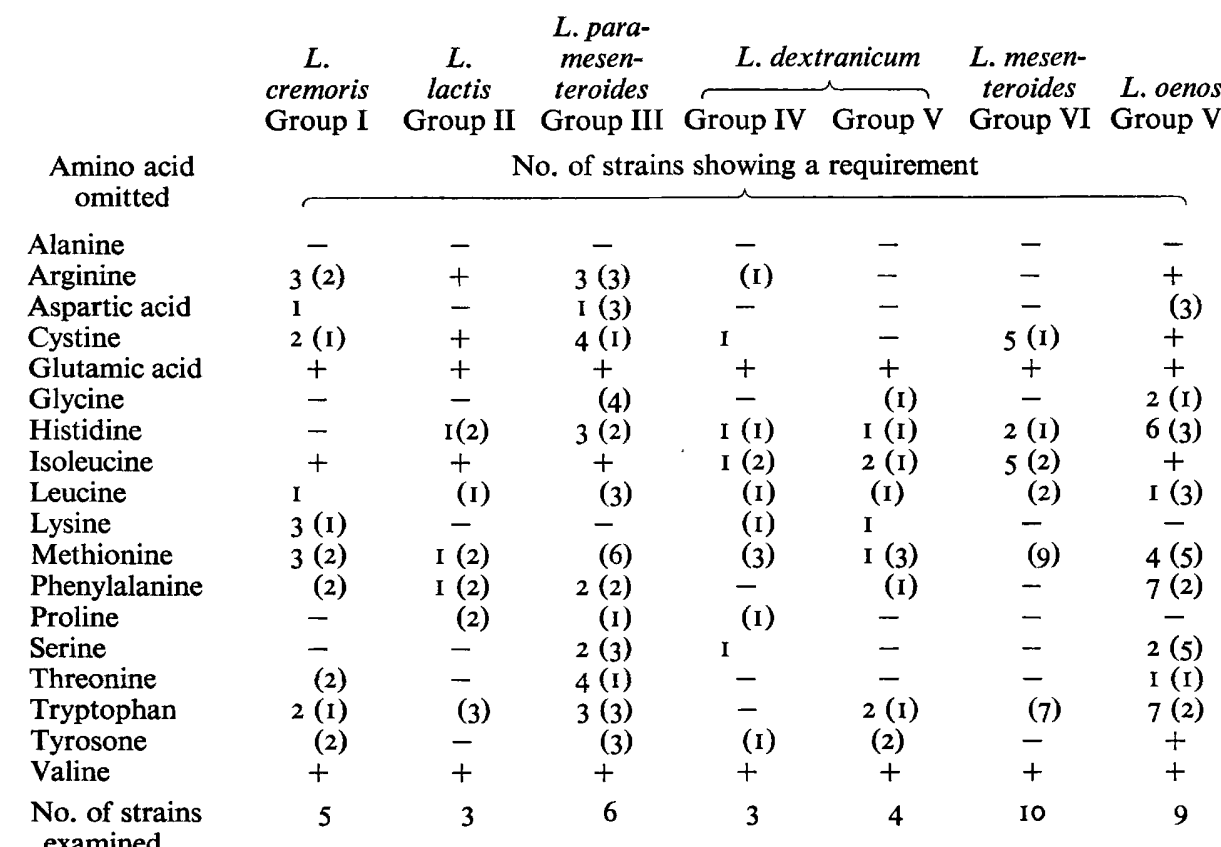

,- no strains require compound; + , all strains require compound.

* Figures in parentheses are the number of strains to which the compound was stimulatory; figures not in parentheses the number which required the compound.

Table 4. Numbers of amino acids essential or markedly stimulatory to culture (basal medium $A$ )

\begin{tabular}{|c|c|c|c|c|c|c|c|c|c|c|c|c|c|c|c|c|}
\hline \multirow[b]{2}{*}{ Species } & \multirow{2}{*}{$\begin{array}{c}\text { No. of } \\
\text { strains } \\
\text { examined }\end{array}$} & & \multicolumn{14}{|c|}{ No. of amino acids required by strains } \\
\hline & & I & 2 & 3 & 4 & 5 & 6 & 7 & 8 & 9 & 10 & I I & 12 & 13 & 14 & 16-18 \\
\hline roides, Group VI & Io & $\cdot$ & . & 3 & $\mathbf{I}$ & I & 2 & I & 2 & . & . & . & . & . & . & . \\
\hline nicum, Group V & 4 & . & . & . & I & $\mathbf{I}$ & $\mathbf{I}$ & . & . & . & $\cdot$ & $\mathbf{I}$ & . & . & . & . \\
\hline Group IV & 3 & . & . & . & . & $\mathbf{I}$ & . & I & - & $\mathbf{I}$ & . & . & . & . & . & . \\
\hline $\begin{array}{l}\text { esenteroides } \\
\text { III }\end{array}$ & 6 & . & . & . & . & . & . & . & I & . & . & $\cdot$ & I & $\mathbf{I}$ & 2 & . \\
\hline Group II & 3 & . & . & . & . & . & - & . & . & $\mathbf{I}$ & I & I & . & . & . & . \\
\hline ris, Group I & 5 & . & . & . & . & . & I & I & . & I & I & I & . & . & . & . \\
\hline Group VII & 9 & . & . & . & . & . & . & . & . & . & $\mathbf{I}$ & 3 & 2 & 3 & . & . \\
\hline
\end{tabular}

\author{
L. mesenteroides, Group VI \\ L. dextranicum, Group V \\ Group IV \\ L. paramesenteroides \\ Group III \\ L. lactis, Group II \\ L. cremoris, Group I \\ L. oenos, Group VII
}

The growth factor requirements do not give a clear-cut division into groups; however, the results do support the classification based on other characteristics. Only a few strains of group VI, but most strains of groups IV and V, require riboflavin, which was also required by all the strains which do not form dextran. Groups II and III are 
separated by their requirement for folic acid. Group I requires more vitamins than any other species. In common with group VII, group I strains did not grow when adenine, guanine, xanthine and uracil were omitted together from the medium.

Table 5. The influence of vitamins, purines, uracil and oleate on the growth of leuconostocs

Medium B was used and various components omitted. No strains showed a requirement for guanine, adenine or xanthine when these were omitted separately. No strains required vitamin $\mathbf{B}_{12}$ (cobalamin) or $p$-aminobenzoic acid. All strains required nicotinic acid+ thiamine + pantothetnic acid + biotin.

Figures in parantheses give the numbers of strains which showed slight growth only. Figures not in parentheses give the number of strains which showed a requirement for the given compound.

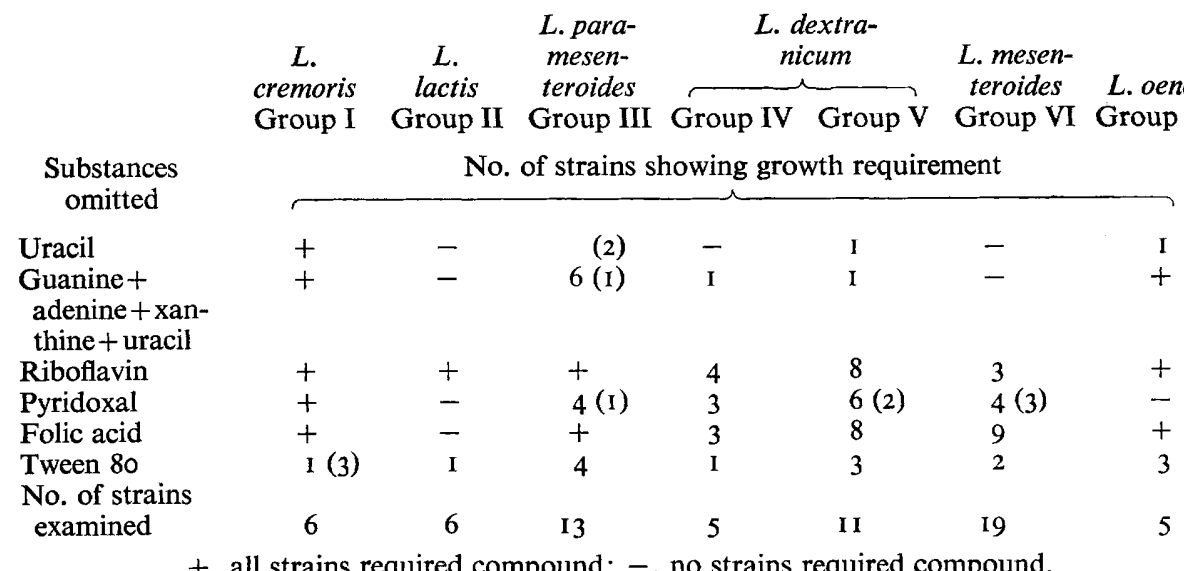

Table 6. The growth of Leuconostoc dextranicum NCDO $5 I 7$ in basal medium B minus adenine, guanine, xanthine and uracil and with these bases added in various admixtures

Concentration of each base $5 \mu \mathrm{g}$. $/ \mathrm{ml}$. medium Substances added

Growth*

Medium B minus 4 bases

Guanine

Adenine

Uracil

Xanthine

Guanine+uracil

Guanine+adenine

Guanine + xanthine

Adenine + xanthine

Uracil+ xanthine

Adenine + uracil + xanthine

Guanine + uracil + xanthine

Guanine + adenine + xanthine

Guanine + adenine + uracil

Guanine + adenine + uracil + xanthine

$$
\begin{gathered}
+++ \\
- \\
+++ \\
++++ \\
++ \\
+ \\
+ \\
\pm \\
+++ \\
++++ \\
++++ \\
\pm \\
\pm \\
++++ \\
++++
\end{gathered}
$$

i.e. complete medium B

* Growth. - , no growth; \pm , very slight growth;,,,++++++++++ , increasing turbidity in the culture. 
The purine and pyrimidine requirements of Leuconostoc dextranicum NCDO 517

Leuconostoc dextranicum NCDO 517 grew when adenine, guanine, xanthine and uracil were all omitted together from the medium. When each substance was omitted singly growth failed when either adenine or uracil was absent. Media were prepared without any of these bases and the effect of adding them separately and in different mixtures is shown in Table 6. At the concentrations used, guanine, and to a lesser extent xanthine, were inhibitory. The inhibition was overcome by the addition of uracil +adenine. Of the other strains examined, those which failed to grow when uracil alone was absent from the medium did not grow when adenine, guanine and xanthine were also omitted.

\section{DISCUSSION}

The present results and those previously reported in the literature do not show wide differences, and those there are may well be due to variations in technique. The results reported by Prouty (196I) show the greatest differences from the present observations. He studied strains of Leuconostoc citrovorum and $L$. dextranicum isolated from dairy starter and cultured butter-milk, and found that the number of amino acids required for both species varied from 7 to 15 . L. dextranicum forms dextran and Prouty's results, if compared with Table 4 , are more in keeping with a non-dextran former than with a dextran former. Prouty pointed out the discrepancy between the numbers of amino acids required and the numbers required by strains studied earlier by Dunn et al. (1947). While Dunn et al. (1947) called three of their strains L. citrovorum it is doubtful whether any of the leuconostocs used were unable to form dextran. Of those called L. citrovorum, strain ATCC 808I is a pediococcus and two, ATCC 797 (NCDO 824) and ATCC 8082 (NCDO 8I2), both form dextran. The fourth strain ATCC 7013 is not in the NCDO, but Camien et al. (1947) pointed out that ATCC 70I3, together with ATCC 797 and ATCC 8358 (L. dextranicum), have sugar fermentation patterns characteristic of $L$. mesenteroides.

Garvie (1960) divided the genus Leuconostoc into six groups and these divisions are supported by the present results on the amino acid and growth factor requirements. These six groups were placed in four species designated Leuconostoc cremoris (group I), L. lactis (group II), L. dextranicum (group IV) and L. mesenteroides (groups III, V and VI). The additional information now available indicates that the demarcation into species can be improved, and it is suggested that the genus be divided into six species, the four named above and two additional ones for which the names $L$. paramesenteroides and $L$. oenos are proposed.

Leuconostoc cremoris (group I) remains unaltered. Whittenbury (I966) found that some strains included in this species gave rise to 'sucrose-fermenting mutants', but these mutants were in other respects identical with the parent culture. He goes on to state that 'the sucrose-fermenting mutants could be regarded as non-dextran forming variants of $L$. dextranicum'. However, there are other differences between $L$. cremoris and $L$. dextranicum than the ability to ferment sucrose and to form dextran. The 'sucrose-forming mutants' of $L$. cremoris would only be confused with $L$. dextranicum if the division into species were based on the minimal tests suggested by Hucker \& Pederson (193I), i.e. the fermentation of arabinose, xylose and sucrose.

Leuconostoc lactis (group II). This group, also, remains unaltered. Whittenbury (I966) found this species to be slow growing. However, in this laboratory L. lactis 
has not been observed to be slow growing and is more active than either L. cremoris or L. oenos.

Leuconostoc paramesenteroides (group III). Previously this group was regarded as a non-dextran forming variant of $L$. mesenteroides. The differences in carbohydrate fermentation were not considered significant in view of the claims that dextran formation was a variable characteristic (Pederson \& Albury, I955). Other workers have been unable to confirm these observations (Whittenbury, 1966). The differences in the numbers of amino acids required by dextran and non-dextran formers, together with the difference in riboflavin and folic acid dependence, suggest that group III is not a variant of the dextran-forming $L$. mesenteroides. With this information available, other differences between groups III and VI become more significant. Generally the dextranforming strains give a gassy acid clot in yeast glucose litmus milk while the non-dextran formers often fail to clot the milk and if they do it is seldom gassy, indicating less vigorous growth. The non-dextran formers fail to hydrolyse salicin and generally fail to hydrolyse aesculin, while the dextran formers generally hydrolyse both glucosides. A new species is proposed on the evidence now available, with NCDO 803 as type strain. Details of properties of 17 strains of this species (other than amino acid and growth factor requirements) were given earlier (Garvie, 1960).

Leuconostoc dextranicum (groups IV and V). Earlier Garvie (I960) suggested that group V should be placed with $L$. mesenteroides rather than $L$. dextranicum, following the classification of Hucker \& Pederson that only strains failing to ferment arabinose and xylose were placed in L. dextranicum. The species described in Bergey's Manual (1957) do not include strains which form dextran and which ferment xylose but not arabinose. Ørla-Jensen (1942) included such strains in Betacoccus bovis and excluded them from $B$. arabinosaceus. The vitamin and amino acid requirements of the cultures suggest that this is a more satisfactory division, and therefore that the Ørla-Jensen classification should be retained.

Leuconostocs mesenteroides (group VI). This species previously included strains with diverse properties and if both groups $\mathrm{V}$ and III are placed elsewhere a more clearly defined species is left.

Leuconostoc oenos. This species is described by Garvie (1967). It is considered that it resembles most closely $L$. paramesenteroides, but the differences separating the species are considered significant and both species should be recognized.

The author wishes to thank Mr B. A. Phillips for valuable technical assistance.

\section{REFERENCES}

Bergey's Manual of Determinative Bacteriology (1957). $7^{\text {th }}$ ed. Ed. by R. S. Breed, E. G. D. Murray and N. R. Smith, London: Baillière, Tindall and Cox Ltd.

Broquist, H. P. \& SNell, E. E. (1948). On the interaction of avidin and oleic acid. J. biol. Chem. 173 435.

Broquist, H. P. \& SNeLl, E. E. (I95I). Biotin and bacterial growth. I. The relationship to aspartate, oleate and carbon dioxide. J. biol. Chem. 188, 43 I.

Camien, M. N., Dunn, M. S. \& Salle, A. J. (1947). The effect of carbohydrates on acid production by twenty-four lactic acid bacteria. J. biol. Chem. 168, 33 .

Dunn, M. S., Shankman, S., Camien, M. N. \& Block, H. (1947). The amino acid requirements of twenty-three lactic acid bacteria. J. biol. Chem. I68, I.

Ford, J. E., Perry, K. D. \& Briggs, C. A. E. (I958). Nutrition of lactic acid bacteria isolated from the rumen. J. gen. Microbiol. 18, 273. 
Garvie, E. I. (1960). The genus Leuconostoc and its nomenclature. J. Dairy Res. 27, 283.

GARVIE, E. I. (I967). Leuconostoc oenos sp.nov. J. gen. Microbiol. 48, 43 I.

GARviE, E. I. \& MABbiTT, L. A. (1967). Stimulation of the growth of Leoconostoc oenos by tomato juice. Arch. Mikrobiol. 55, 398.

Hucker, G. J. \& Pederson, C. S. (I931). A study of the physiology and classification of the genus Leuconostoc. Zentbl. Bakt. (Abt. II), 85, 65.

Knudsen, S. \& Søresnen, A. (1929). Bidrag til syrevaekkernes Bakteriologi. Den Kgl. Veterinaerog Landbohojskole Aarsskrift 64.

Ørla-Jensen, S. (1942). The Lactic Acid Bacteria. Copenhagen: Ejnar Munksgaard.

Pederson, C. A. \& Albury, M. N. (1955). Variation among the heterofermentative lactic acid bacteria. J. Bact. 70, 702 .

Peynaud, E., Lafon-Lafourcade, S. \& DomercQ, S. (I965). Besoin nutritionnels de soixante-quatre souches de bactéries lactiques isolées de vins. Bull. Off. int. Vin. 38, 945.

Prouty, C. C. (1961). Amino acid requirements of Leuconostoc citrovorum and Leuconostoc dextranicum isolated from dairy starters and cultured milk products. J. Dairy Sci. 54, 2 I 00.

RADLER, F. (1958). Untersuchung des biologischen Säureabbausim Wein. II. Der Nähr- und Wuchsstoffbedarf der Äpfelsäure-abbauenden Bakterien. Arch. Mikrobiol. 32, I.

Reiter, B. \& OrAm, J. D. (1962). Nutritional studies on cheese starters. I. Vitamin and amino acid requirements of single strain starters. J. Dairy Res. 29, 63.

Roberts, E. C. \& SNELl, E. E. (1946). An improved medium for microbiological assays of Lactobacillus casei. J. Biol. Chem. 163, 499.

Rogosa, M. \& Sharpe, M. E. (I959). An approach to the classification of the lactobacilli. J. appl. Bact. 22, 329.

Shankman, S., Camien, M. N., Block, H., Merrifield, R. B. \& Dunn, M. S. (1947). Vitamin requirements of lactic acid bacteria. J. biol. Chem. 168, 23.

Whiteside-Carlson, V. \& Carlson, W. C. (I949). The vitamin requirements of Leuconostoc for dextran synthesis. J. Bact. 58, 135 .

Whiteside-Carlson, V. \& Rosano, C. L. (I95I). The nutritional requirements of Leuconostoc dextranicum for growth and dextran synthesis. J. Bact. 62, 583 .

Whittenbury, R. (1966). A study of the genus Leuconostoc. Arch. Mikrobiol. 53, 317. 